\title{
Proširene vene
}

\author{
Dragana Ivanović \\ ZU Apoteka Požarevac, Golubac, UFTS Sveti Sava
}

\section{Uvod}

Proširene vene su dominatno oboljenje površnog venskog sistema. Pod proširenim venama podrazumevamo dilatirane i izvijugane površne vene donjih ekstremiteta. Bolest je lake prirode i bezopasna po život. U razvijenim zemljama predstavlja socijalno - medicinski problem zbog velike učestalosti i ograničene radne sposobnosti obolelih.

\section{JESTE LI ZNALI?}

\section{Proširene vene se ne javljaju kod četvoronožnih životinja}

\section{Anatomija i fiziologija vena}

Celokupni krvotok ljudskog organizma delimo na:

- Sistemska (opšta) cirkulacija

- Pulmonarna (plućna) cirkulacija

Sistemsku cirkulaciju nazivamo još i veliki krvotok ili periferna cirkulacija, jer ova cirkulacija krvlju snabdeva sva tkiva i organe osim pluća.

Arterije prenose krv do tkiva pod velikim pritiskom pa su i njihovi zidovi jaki, one se granaju i na kraju svakog arterijskog sistema su arteriole kroz koje se krv propušta u kapilare. U kapilarima se vrši razmena tečnosti, hranIjivih materija, elektrolita, hormona i gasova. Krv iz kapilara dolazi u venule gde se sakuplja i kreće nazad ka srcu. Venule se stapaju u sve veće krvne sudove. Pritisak u venama je nizak pa su ovi krvni sudovi tanki. Vene su krvni sudovi različite dužine i različitog promera. Zidovi vena se sastoje iz 3 sloja:

- Spoljašni omotač sastoji se uglavnom od vezivnog tkiva

- Srednji omotač sastoji se od glatkih mišićnih vlakana i elastičnog tkiva (kontrakcija ovog omotača smanjuje promer krvnog suda)

- Unutrašnji omotač - vezivno tkivo prevučeno slojem pločastih ćelija

Za razliku od građe arterija zid vena ima manje elastičnih vlakana i mišićnih ćelija pa im zid nije tako čvrst i elastičan. U unutrašnjem zidu vena su zalisci koji se otvaraju u pravcu proticanja krvi i ne dozvoljavaju povratak u suprotnom pravcu.

Sve vene možemo podeliti na: površinske i duboke. One su spojene sistemom spojnih vena.

Duboke vene obično prate duboke arterije i idu uz njih. Uz jednu arteriju obično idu dve duboke vene koje nose isti naziv kao i arterija koju prate.

Površinske vene idu potkožno i ulivaju se u duboke vene. Najveća površinska vena noge je velika potkožna vena v.saphena magna. Potiče iz venske mreže stopala i ide unutrašnjom stranom noge. U gornjem delu prednjeg predela butine završava se, probija fasciju i uliva se u butnu venu. Mala potkožna vena noge v.saphena parva polazi iz površne mreže stopala ali se uliva u zatkolenu venu. Mreža površinskih vena noge je razgranata i različitog oblika. Na kretanje krvi kroz vene utiče:

- Rad srca

- Usisavajuće dejstvo srca i grudnog koša (zbog razlike u pritiscima)

- Kontrakcija telesnih mišića

- Venski zalisci

Regulacija cirkulacije:

- Auto regulacija (potreba tkiva za kiseonikom)

- Nervna regulacija (utiče na širenje krvnih sudova)

- Humoralna regulacija - najčešće uticaj hormona i produkata metabolizma iz krvi koji utiču na glatke mišiće krvniih sudova.

Mišići vena omogućavaju peristaltiku - mogu da se suze ili prošire kako bi bili u mogućnosti da zadrže i veliku i malu količinu krvi. U venama sistemske cirkulacije nalazimo najveću količinu krvi (može da se nađe i do 60\% krvi cirkulacije). Zato je poprečni presek vena u proseku 4 puta veći od preseka odgovarajućih arterija. Brzina toka krvi u svakom segmentu cirkulacije obrnuto je proporcionalna poprečnom preseku krvnog suda. Venski zalisci su tako postavljeni da je tok krvi moguć samo u jednom smeru - u smeru ka srcu. Pri svakom pokretu noge, ili samo ako se napne mišić, vrši se kompresija na vene i krv se istiskuje iz vene. Ovaj sistem za pumpanje je efikasan i poznat kao „venska pumpa“ ili „mišićna pumpa“. Venska pumpa ne radi kada ekstremiteti potpuno miruju. Kao rezultat toga noga otekne ili se smanji volumen krvi.

Venama se krv transportuje od periferije prema srcu i zato je to povratna cirkulacija. Kako su vene većeg lumena od arterija služe kao rezervoar krvi u organizmu. Krv se u venama kreće sporo. Zid vena je mnogo tanji od arterijskog, ima manje mišićnog i elastičnog tkiva. Njihova anatomska osobenost je da imaju zaliske - valvule.

\section{Uzroci nastanka proširenih vena}

Kada se govori o proširenim venama misli se na površinske vene.

„varikozan" (lat.) - proširen

U osnovi većine venskih oboljenja nalazi se oštećenje venskih zalistaka ili poremećaj protoka krvi zbog ugrušaka - venskih tromboza.

Varikozne vene nastaju kada zalisci venskog sistema budu razoreni patološkim procesima. Takve vene su pro- 
širene duži vremenski period dok su dimenzije venskih zalistaka ostale iste. To se najčešće dešava kod trudnica ili kod osoba koje veći deo radnog vremena stoje. Oštećene valvule nikada više se neće potpuno zatvoriti $i$ sprečavati tok krvi u suprotnom smeru. U situaciji kada zataji venska pumpa, pritisak u venama noge raste, a to vodi daljem proširenju vena i potpunom uništenju valvula. Tako nastaju varikozne vene - kvrgava ispupčenja ispod kože. $U$ isto vreme pritisak u venama i kapilarima postaje jako visok, pa izlaskom tečnosti iz kapilarne krvi u tkivima nastaje edem. Ovaj edem sprečava kapilarnu razmenu gasova i hranjivih materija između kapilara i ćelija mišića i kože, pa mišići postaju slabi i bolni, a koža prvo atrofira i na kraju se razvije ulkus ili gangrena. Takve noge dobro je odmoriti dizanjem u visini srca i zavijanje noge kompresivnim zavojima da bi se umanjio edem i u krajnjem slučaju njegove posledice.

\section{Kliničke manifestacije venskih oboljenja}

\section{ZABLUDA:}

Bolest proširenih vena u trudnoći se tretira kao estetski problem. Naime, trudnoća je stanje gde je povećana sklonost ka nastanku tromboze što može ugroziti život majke i deteta.

1. Oboljenje površnog venskog sistema

1.1. Proširene vene (varices)

1.0.1. primarni varikoziteti

1.0.2. sekundarni varikoziteti

1.2. Komplikacije varikoziteta

1.1.1. tromboza i zapaljenje - thrombophlebitis

1.1.2. krvarenje, sekundarne lezije i venska ulceracija - ulcus venosum

2. Oboljenje dubokog venskog sistema

1.1. Duboka venska tromboza - phlebothrombosis profunda

1.2. Komplikacije duboke venske tromboze-embolija pluća, hronična venska insuficijencija, otok i na kraju venska ulceracija.

\section{Etiologija}

- još uvek nije razjašnjeno kod čoveka su nepovoljni hemodinamski uslovi u donjim ekstremitetima, jer se krv vraća prema srcu nasuprot sili zemljine teže - zbog uspravnog stava i dvonožnog kretanja.

Postoje dve teorije šta je uzrok nastanka proširenih vena:

1. Insuficijencija valvula - što omogućava vraćanje krvi i povećanje pritiska u distalnim segmentima.

2. Slabost venskih zidova

Nastankom proširenih vena dolazi do otežanog vraćanja krvi u duboke vene, dolazi do venske staze i povećanog venskog pritiska (hronične venske insuficijencije) u koži i potkožnom tkivu. Sekundarne proširene vene predstavljaju komplikaciju oboljenja dubokih vena.

Blaži stadijum varikoznih vena je više estetski problem i ne traži medicinski tretman. Stanje vremenom može da se pogorša do te mere da kod najtežih slučajeva bude zastupljena ozbiljna venska insuficijencija. Krv se sve teže vraća u srce, što može da izazove stvaranje krvnih ugrušaka i ozbiljnih infekcija. Krvni ugrušci mogu izazvati zastoj u radu srca ili pluća, a koža oko proširenih vena može biti bolno osetljiva na dodir, noga može oteći i javiti se ulceracije.

Žene su više izložene ovom oboljenju. Faktori rizika kod žena:

- promene u nivou hormona u krvi u vreme menopauze, trudnoće i pred menstruaciju

- korišćenje kontraceptivnih pilula ili hormonske supstitucione terapije

- genetski faktor

- gojaznost

U toku trudnoće ukupna zapremina krvi se povećana pa je to dodatni napor za vene. Veća količina estrogena dovodi do dilatacije zidova vena i usporava kretanje krvi u njima. Plod može vršiti pritisak na venu cavu.

\section{Venska tromboza}

Tromboembolijski poremećaji kardiovaskularnog sistema povezani su sa formiranjem tromba i embolusa u krvnim sudovima.

Tromb je abnormalni, nepokretan krvni ugrušak sastavljen od fibrina, trombocita i ostalih ćelijskih elemenata. On će se u jednom momentu odvojiti zbog stalnog protoka krvi.

Ugrušak koji slobodno plovi - embolus - je fragment krvnog ugruška.

Tromboza je okluzija vene ili arterije od strane tromba. Embolija ili tromboembolija je okluzija krvnog suda embolusom.

Emboli se ne zaustavljaju sve dok ne dođu do uskog grla u cirkulaciji. Oni koji potiču iz velikih arterija ili iz leve strane srca začepe male sistemske arterije. Emboli koji potiču iz venskog sistema ili iz desne strane srca dolaze do plućnih krvnih sistema i uzrokuju plućnu emboliju.

Uzroci tromboembolijskih stanja:

- hrapava endotelna površina krvnog suda - uzrok su arterioskleroza, infekcija ili trauma

- spor tok krvi kroz krvni sud

Tromboembolija može da se javi u bilo kom delu cirkulacije. Za njen nastanak bitni su sledeći činioci:

- hiperkoaguabilna stanja krvni (posledica trudnoće, maligniteta, postojanje antitela, npr. kod autoimunih bolesti),terapije estrogenima - primena oralnih kontraceptiva ili hormonske supstitucione terapije.

- oštećenje endotela krvnog suda - npr. itravenskim kateterom

Venska tromboembolija obično je posledica staze krvi. Venski tromb obično ima „crveni rep " fibrina koji ima mogućnost da začepi vene. On se obično odvaja i formira embolus. Tromboza u venskoj cirkulaciji izaziva edem i inflamaciju tkiva. Venska tromboembolija postoji kod svih hospitalizovanih pacijenata koji su podvrgnuti hirurškoj intervenciji, mada stepen zavisi od težine intervencije, starosti pacijenta, prisustva drugih bolesti. Zastupljena je i kod druge duže imobilnosti: dugo sedenje pri putovanju i poseban rizik su trudnoće.

Tromboza dubokih vena je najčešći tip venske tromboze. Karakteriše se bolom, otokom, noga je topla, često cija- 
nozna, opipljiv je čvor. Njena najčešća komplikacija je plućna embolija - kada deo tromba migrira i zapuši plućnu arteriju.

\section{ZABLUDE:}

\section{1. operacijom obolela vena se odstranjuje pa se ne može „vratiti“. Ako operisani pacijent ne ukloni faktore rizika mogu se javiti novi problemi.}

\section{2. ukoliko postoje, a ne leče se, proširene vene spontano ne prolaze.}

\section{Profilaktičke metode}

- fizičke - povećanje venskog protoka: brzo ustajanje nakon operacije, podizanje nogu, nošenje kompresivnih zavoja ili čarapa

- farmakološke metode - primena antikoagulanasa: heparin ili oralni antikoagulansi

\section{Tromboflebitis}

Predstavlja kombinaciju tromboze i flebitisa - inflamacija površinske vene bilo koje lokalizacije. Tromboflebitis je pojava tromba sa jedne strane i pojava inflamatorne reakcije zida površinskih vena. To je česta pojava kod varikoziteta donjih ekstremiteta, naročito kod ženskog pola. Može dovesti do septikemičnih apcesnih i embolijskih komplikacija.

Uzroci nastanka:

- oštećenje endotela zida vene

- usporeni venski krvotok

- hiperkoaguabilnost krvi

Ovi uzroci su zastupljeni kod:

- varikoziteta

- trauma vena

- dugotrajnog ležanja u krevetu

- korišćenja oralnih kontraceptiva

- septička stanja

- maligne inflamacije zidova vena

\section{Klinička slika}

Zapaljenjske i inflamatorne promene najčešće su u varikoznim venama butine i potkolenice. Taj deo vene je indusiran (otvrdnuo) pa se palpira kao otvrdnuće u obliku olovke, bolno je, a koža iznad vene je edematozna (otečena) i eritematozna (crvena), telesna temperatura je povišena. Kada posle nekoliko dana tromboflebitis regredira, u vezivnom tkivu zahvaćenog segmenta vene zaostaje deo vezivnog tkiva (fleboskleroza). Recidivi su česti. Dijagnoza se postavlja na osnovu anamneze, kliničke slike, dermatološkog pregleda i ultrazvučni dopler krvnih sudova.

\section{Lečenje}

- nesteroidni antireuamatici

- salicilati i inhibitori agregacije trombocita

- antibiotici - indikovani samo kod septičkih stanja

- lokalno se koriste heparinski preparati
- alkoholne obloge

- elevacija obolele noge

- ukloniti sve faktore koji pospešuju nastanak tromboflebitisa

- savetuje se hodanje zbog aktiviranja mišićne pumpe (mirovanje i pasivno stajanje pogoduje rastu tromba)

- parenteralno - niskomolekularni heparin

Lečenje obično traje 3-6 nedelja. Najčešće komlikacije su pojava apscesa, sepse i embolije.

Tromboflebitis najčešće počinje u potkolenom segmentu i napreduje naviše. Može zahvatiti v.saphenu magnu. Tromboza ove vene može dati proksimalnu propagaciju tromba i embolije. Kod takvih stanja neophodno je hirurško lečenje, upotreba niskomolekularnog heparina radi prevencije propagacije trombovskog procesa. Kod površinskih variksa može se vršiti incizija i evakuacija trombne mase.

Najčešći simptomi su:

1. osećaj težine u nogama na kraju dana ili posle dužeg stajanja

2. svrab na koži i bolni grčeve tokom noći

3. otoci u predelu skočnog zgloba koji se povlače tokom noći ili podizanjem ekstremiteta

\section{Stadijumi i tok bolesti kod proširenih vena}

Bolest najčešće prolazi asimptomatski i praćena je samo estetskim problemima

Na osnovu progresije bolesti mnogi autori uobičavaju podele na četiri klinička stadijuma:

1. stadijum proširenih vena - kozmetičke (estetske promene)

Nema poremećaja venske cirkulacije, prošireni venski sudovi su mrežastog, metličastog izgleda.

2. stadijum proširenih vena

Venska proširenja su veća, lokalizovana uglavnom oko skočnog zgloba i na stopalu i tu se posle dužeg stajanja može javiti otok. Najčešći simptomi: bolovi, osećaj napetosti i nadutosti nogu, povišena lokalna temperatura i osećaj težine u nogama. Tegobe su uglavnom izražene noću.

3. stadijum proširenih vena

Potkožne vene su proširene do debljine prsta, izuvijane, često sa znacima tromboflebitisa (fiksiranog ugruška) i promenom u boji okolne kože. Ovde su oštećeni zalisci na ušću površnih u duboke vene. Poremećaj u venskom protoku uzrokuje oštećenje limfne i mikrocirkulacije. Simptomi: bolovi, osećaj nadutosti, grčevi noću, trnjenje, otoci pri stajanju, jača prokrvljenost kapilara, oštećenje kože u predelu stopala i skočnog zgloba.

4. klinički stadijum proširenih vena

Zastupljene su trofičke promene kože i potkožnog tkiva. Variksi su slabo ili enormno ispunjeni. Karakteristična je kožna promena koja je prouzrokovana venskim zastojem. Kožna oštećenja mogu biti: dermatitična, ekcematoidna, pigmentna i dr. Podkožno tkivo i koža postaju sve više istanjeni, atrofična, ljuspasta i edematozna. Česte su venske razjedine (ulkus venosum) bilo hipostatičkog ili postrombotskog toka. U 
terminalnoj fazi variksi su skloni prskanju pri lakšim ozledama. Ako je koža istanjena može nastati obilno spoljašnje vensko krvarenje. U razvijenim variksima dolazi do zastoja krvi, pa mogu nastati tromboze, koje ako se šire mogu zahvatiti i glavna površinska stabla pa su česte i tromboembolijske komlikacije.

\section{Dijagnoza}

- osnovna dijagnoza utvrđuje se inspekcijom u uspravnom stavu bolesnika

- palopacijom se otkrivaju trombozne mase unutar variksa

- EHO Doppler ultrazvuka (smanjuje upotrebu flebografije ili drugih invazivnih metoda)

\section{Plan lečenja proširenih vena}

- konzervativno

- sklero-kompresivno

- hirurško

VENEKTAZIJA

- uvećanje, hipertrofija

- ravnomerno proširenje venskog stabla izazvano povećanim protokom venske krvi (kod sportista i fizičkih radnika)

\section{ZABLUDA: pogrešno uverenje: da obolelim venama nema leka}

\section{Konzervativna terapija}

Sastoji se u davanju saveta i ima niz mera da bi se sprečila progresija bolesti i tegobe pacijenata.

Svrha nošenja elastičnih zavoja ili čarapa je da se spoljašnjom kompresijom na proširene vene ne dozvoli njihovo punjenje krvlju.

Zavoji i čarape moraju imati odogovarajuću veličinu i čvrstinu. Stavljaju se samo ujutru odmah posle buđenja u ležećem položaju. Noga koja se povija treba da je podignuta iznad grudnog koša čime su stvoreni hemodinamski uslovi da se prazne venski depoi i sudovi noge. Zavoj se plasira od prstiju na stopalima sve do prepona. Svaki sledeći nivo zavoja pokriva najmanje jednu polovinu do jedne trećine prethodnog navoja. Kako je potrebno da je noga podignuta elevaciju je najbolje da uradi neka druga osoba. U početku zavoj treba da je blago zategnut a kasnije više.

Pacijentu sa ulceracijama ili alergijom na gumu stavlja se prvo lokalno obloga, 3-4 sloja gaze pa tek onda elastični zavoj. Elastične čarape se plasiraju na sličan način, stim da treba voditi računa da se ne stvaraju nabori koji bi usporili vensku cirkulaciju. Svrha ovih kompresija je da se postigne pritisak na duboki venski sistem i nadoknadi gubitak funkcije mišića. Time se ujedno pospešuje protok krvi kroz vene.

\section{Sklero - kompresivna terapija}

Često se upotrebljava i još češće zloupotrebljava. Princip metode: $u$ ispražnjeni venski sud gde ne preti moguć- nost nastanka i širenja tromba ubrizga se sklerozantno sredstvo. Vena se potom komprimuje tupferom, i drži pod elastičnim zavojem najmanje dve nedelje. Komplikacije ove metode: postinjekcioni ulkus, venska tromboza, pigmentacija i zadebljanje kože, alergijske i anafilaktičke reakcije.

\section{Hirurško lečenje}

Neophodno je ako preventivne mere, sklorozantna i druga terapija ne daju rezultate, ako dođe do tromboflebitisa, hroničnog venskog zastoja, embolija pluća i ako dođe do krvavljenja varikoziteta ili ako se insistira iz estetskih razloga.

\section{Lečenje po stadijumima}

- 1.stadijum - lokalno se koriste masti i po potrebi antiagregaciona terapija. Preventivna mera je upotreba elastičnih zavoja ili čarapa, fizička aktivnost, redukcija telesne težine, izbegavanje dugog stajanja.

- 2.stadijum - nastavlja se primena elastične bandaže, preventivnih mera, antiagregaciona terapija i sklerozantna terapija.

- 3. i 4.stadijum - zahteva operativno lečenje.

Ima antioksidativno i vazodilatatorno dejstvo. Kontraidikovana je upotreba kod trudnica, doilja, dece, osoba koje koriste antikoagulante i osoba koje čekaju hiruršku intervenciju. Interakcije: istovremena upotreba sa antikoagulantnim lekovima, nesteroidnim antiinflamatornim lekovima, acetilsalicilnom kiselinom jer može dovesti do pojačanog krvarenja.

\section{Farmakološke metode}

Koagulacija krvi odvija se u nekoliko faza. Započinje agregacijom trombocita i posle nekoliko procesa završava se formiranjem fibrina. Ovu lančanu reakciju mogu prekinuti lekovi iz nekoliko grupa. U oblasti ovih lekova desile su se velike promene, uvedeni su novi lekovi pa se podela prema mehanizmu dejstva deli na:

- antagonisti vitamina $\mathrm{K}$ - nekadašnji oralni antikoagulansi - varfarin, acenokumarol

- direktni inhibitori trombina

Antikoagulantna terapija kreće heparinom frakcionisanim i nefrakcionisanim u vidu intravenske bolus injekcije. Posle njega obično se daju antagonisti vitamina K. Trombolitici omogućavaju brzu lizu tromba i na taj način se čuvaju venske valvule. Po potrebi se daju antibiotici i analgetici.

Flebotonički i vazoprotektivni lekovi povećavaju otpornost kapilara, smanjuju eksudaciju i vrše zaštitu endotela kao posledicu venske staze. Koriste se kod blagih tegoba. Registrovani oralni preparati su diosmin, diosminthesperidin, trokserutin.

Lokalno se koriste gelovi i masti koji sadrže heparin čime se ubrzava resorpcija edema. Uspešno se koristi kod tromboflebitisa. Iz mastocita posle povrede tkiva oslobađa se histamin koji učestvuje u inflamatornim procesima. Heparin se vezuje za histamin i tako se smanjuje inflamacija.

Ginkgo biloba - poreklom je iz Kine, dugogodišnja biljka. Danas se gaji u svim delovima sveta. Od lišća ove biljke 
spremaju se ekstrakti i tinkture. Aktivna jedinjenja su polifenoli i diterpenska jedinjenja.

Aesculus hippocastanom - divlji kesten je drvenasta višegodišnja biljka balkanskog poluostrva. Od njega se koristi seme i kora, ređe cvet. Seme sadrži: skrob, saponine, ulja, glikozide, eskuline, sterole. Kora sadrži: tanine, eskulin. Cvet sadrži: tanine, i kvercitrin. Dejstvo flavonoida i tanina ispoljava se na povećanju otpornosti kapilara i smanjivanju njihove propustljivosti.

Vitis vinifera - vinova loza je bogata taninima, flavonoidima, i leukoantocijanom. Svojstvo vitamina P (flavonoidi) je da su dobri hemostatici.

Kada su u pitanju lekovi iz grupe antikoagulanasa, a najčešće je u pitanju varfarin mora da se ima u vidu da se metabolizuje u jetri preko izoenzima CYP 450 pa su moguće mnoge interakcije: indukcija i inhibicija kako sa lekovima koji se metabolizuju istim putem tako i sa hranom bogatom vitaminom K (spanać, brokoli, kelj, blitva, karfiol, kupus). U interakcije stupa i sa biljnim preparatima kantariona, žen - šena, zelenog čaja, ginko - bilobom, belim lukom, brusnicom, vitaminom E, glukozaminom. Najčešće interakcije varfarina su sa: amjodaron, azolni antimikotici, statini - fluvastatin, rosuvastatin, simvastatin, fibrati, antibiotici (sulfametoksazol trimetoprin, metronidazol, makrolidi izuzev azitromicini, hinoloni - ciprofloksacin, acetilsalicilna kiselina, klopidogrel i neki antidepresivi).

$\mathrm{U}$ interakciji acetilsalicine kiseline i varfarina dolazi do ozbiljnog krvarenja, a kod acetilsalicine kiseline i ibuprofena smanjuje se antiagregacijski efekat.

\section{Nefarmakološke mere}

- izbegavati sedenje i stajanje u jednom položaju više od 30 minuta i sedenje sa prekrštenim nogama

- izbegavati neudobnu obuću sa previsokim ili preniskim potpeticama, dokolenice sa jakom gumom

- vežbati i baviti se sportom: hodanje, gimnastika, vožnja bicikla, plivanje

- regulisati telesnu težinu

- ne nositi usku odeću oko struka, nogu, prepona

- rizične grupe trebalo bi da nose elastične zavoje ili čarape

- vodite računa o ishrani sa što manje soli i više biljnih vlakana
- u toku dana podići noge iznad nivoa srca kako bi se u njima poboljšala cirkulacija

- izbegavati dugo izlaganje visokim temperaturama: sunčanje, podno grejanje, tople kupke, sauna, električni pokrivači, neposredna blizina grejnog tela.

- svako tuširanje nogu završiti hladnom vodom i masiranjem prema srcu

Elastični zavoji ili čarape vrše kompresiju od članaka prema butinama i pomažu da se zaostala krv vraća u srce i poboljša cirkulacija u nogama. Nose se tokom celog dana. Čarape za vene dostupne su u različitim veličinama, dizajnu i nivou kompresije. Kod kompresije od 10 do $15 \mathrm{mmHg}$ i od 15 do $20 \mathrm{mmHg}$ izbor mogu da naprave sami pacijenti. Za veći nivo kompresije potreban je savet stručnjaka. Da bi se pacijent navikao na čarape u početku je najbolje da ih nosi nekoliko sati, a kasnije ceo dan.

\section{Kada pacijenta uputiti lekaru}

- Ako se pojavi ili pojača bol u nozi koja je natekla

- Ako koža oko proširenih vena počne naglo da krvari

- Ako se krvarenje zaustavlja teško posle lakše povrede

- Ako je edem na nozi bolan na dodir

- Ako je na koži otvoren čir

- Ako se simptomi proširenih vena ne smiruju nakon kućnog tretmana

- Ako je nastalo krvarenje koje ne može da se zaustavi

- Ako je pojačano oticanje ruke ili noge.

\section{Literatura}

1. Guyton A. C. 1985. Medicinska fiziologija (VIII, hrvatskosrpsko, prerađeno i dopunjeno izdanje). Beograd - Zagreb: Medicinska knjiga.

2. Tucakov J. 1990. Lečenje biljem - Fitoterapija.

3. Stajkovac A, Bajić M, Živanović S, Anđelković I. 1980. Anatomija i fiziologija sa praktikumom. Beograd: Zavod za udžbenike i nastavna sredstva.

4. Varagić V, Milošević M. 1986. Farmakologija (peto, prerađeno i dopunjeno izdanje). Beograd - Zagreb: Medicinska knjiga.

5. Kažić T. 2013. Gotovi lekovi - priručnik za farmakoterapiju (XIV izdanje). Beograd: Integra

6. Đorđević B, et all. 2007. Dijetetski suplementi na tržištu Srbije 2010 godine. (Gl. Urednik: Miletić I, Šobajić S.). Beograd: BB-Soft

7. Tomić M, Stepanović-Petrović R. 2011. Terapija anemija i poremećaji koagulacije krvi. Farmakoterapija za farmaceute (Gl. Urednik: Ugrešić N.). Beograd: Farmaceutski fakultet

8. Harison-principi interne medicine. 1997. (Urednici: Ivančević et all.). Split: Placebo 